\title{
Brucella canis and Public Health Risk
}

\author{
İsfendiyar Darbaz (D), Osman Ergene (1) \\ Department of Obstetrics and Gynaecology, Near East University School of Veterinary Medicine, Nicosia, Cyprus
}

ORCID IDs of the authors: i.D. 0000-000I-5I4I-8165; O.E. 0000-0002-7607-4044.

Cite this article as: Darbaz I, Ergene O. Brucella Canis and Public Health Risk. Cyprus J Med Sci 2019; 4(I): 52-6.

\begin{abstract}
Pregnancy losses in dogs are associated with many types of bacteria. Brucella canis is reported to be one of the most important bacterial species causing pregnancy loss in dogs. Dogs can be infected by 4 out of 6 Brucella species (B. canis, B. abortus, B. melitensis, and B. suis). B. canis is a Gramnegative coccobacillus first isolated by Leland Carmichael and is a cause of infertility in both genders. It causes late abortions in female dogs and epididymitis in male dogs. Generalized lymphadenitis, discospondylitis, and uveitis are shown as the other major symptoms. B. canis infections can easily be formed as a result of the contamination of the oronasal, conjunctival, or vaginal mucosa . Infection can affect all dog breeds and people. While morbidity may be high in infection, mortality has been reported to be low. Most dogs are asymptomatic during infection, and it is difficult to convince their owners that their dogs are sick and should not be used in reproduction. The diagnosis of the disease is quite complex. Serological tests may provide false results or negative results in chronic cases. Therefore, diagnosis should be defined by combining the results of serological studies and bacterial studies to provide the most accurate result. No antibiotic treatment is reported to be $100 \%$ effective in B. canis infections, and infected animals are recommended to be removed from other animals and not be used for reproduction for a prolonged period.
\end{abstract}

Keywords: Brucella canis, humans, pathogen, zoonotic

\section{INTRODUCTION}

Brucella infection may form invaginal discharge during abortion or estrous. It may form as a result of the presence of $>10^{10}$ bacteria/mL in postnatal fetus, placenta, or lochia. It may form as a result of receiving these bacteria from oronasal, conjunctival, or vaginal mucosa contact (I-6). Bacteria are spread with sperm in male dogs (7). The infection may develop after copulation of a non-infected female dog with an infected male dog (8). Bacteria are also spread via urine in both genders. Male dogs can have high levels of bacteria in their urine, and this is the reason why male urination can be dangerous. Brucella infection begins to spread via urine after 4-8 weeks of infection (7).

Bacterial concentration in the milk of infected animals is reported to be high (9). The idea of disease spreading with high levels of bacteria in the milk has been a matter of debate (4). While some researchers are defending that milk is insignificant in disease transmission because puppies are infected in the uterus (6), some researchers report that infected milk may be dangerous for environmental contamination (4). Bacterium is isolated in low concentrations from saliva, nose and eye, and feces (I0).

The aborted material of dogs infected with Brucella canis in dog shelters or in co-cultivated environments is very dangerous for non-infected dogs. Waste placenta tissue and fluids may contain high levels of microorganisms. Infection after contamination in shelters can be spread very quickly (5).

Huts, equipment, and people permanently in contact with infected dogs are also reported as sources of infection (II). Infections in humans are usually reported in laboratory workers and shelter workers exposed to sustained or major exposures. Owners who are in constant contact with infected dogs are also reported to be infected. As a result, animal owners should be informed about the potential risk but not alarmed about this zoonotic disease (I2).

\section{CLINICAL SYMPTOMS}

\section{Non-Specific Symptoms}

B. canis-infected dogs may not always show serious clinical symptoms (5). Breeders provide barely or unidentifiable information about the clinical symptoms in B. canis infections. These clinical symptoms are weak hair 
structure, poor, exhausted, overworked, drowsy movements during exercise, weight loss, lameness, lymphadenitis, and changes in behavior (loss of appetite, poor performance) (2). Death has not yet been reported as a primary cause of death in B. canis infections (5).

Fever is rarely seen in B. canis infections, which is explained by the lack of endotoxin-producing lipopolysaccharides in the organism $(2,13,14)$.

Decrease in pregnancy rate, early embryonic death, fetal resorption, and late-period abortions can be seen in female dogs, whereas painful scrotal growth, testicular atrophy, moist scrotal dermatitis, decrease in ejaculatory volume, loss of libido, reluctance to breed, poor quality sperm with white blood cells, and increase in morphological deformation in sperm can be observed in male dogs in examinations usually during the first 3 months of infection $(2,15)$. Discospondylitis, meningoencephalitis, or uveitis may also develop as a symptom in both genders (2).

B. canis affects the active macrophages (intracellular) during infection, causing the growth of lymph node nodules and reticuloendothelial cell hyperplasia. In addition to lymph nodes, spleen and liver growth can be observed. A hardening and a nodular structure in the spleen have also reported (2).

\section{Specific Symptoms}

Reproductive failure has reported to mean abortion, epididymitis, orchitis, and testicular atrophy. The most obvious clinical symptom that can be seen and reported by patient owners is the spontaneous abortions formed in dogs that are assumed to be healthy. These abortions usually occur between days 45 and 59 of pregnancy. Brucellosis can also result in resorption or early embryonic death after mating. Infants born as a result of pregnancies formed in infected animals may die in 20 days on average. Infected dogs have been reported to be able to give birth normally in the following pregnancy, as well as localized autolyzed fetuses, fetal mortality, or normal fetus that die within a few hours may be born. Puppies that are able to survive are bacteremic for several months $(2,4)$.

Long-term, viscous, serosanguinous vaginal discharge following abortion may last for $1-6$ weeks. This discharge may contain high amounts of bacterial colonies and can be a major problem in infecting patient owners and other dogs. Necessary precautions and warnings must be made against contagion that can occur as a result of contamination with mouth, respiratory tract, or waste material and liquid to protect people and other dogs. Brucellosis does not affect estrus symptoms and mating. Dogs can continue to mate after two or three abortions and then have a normal birth $(2,4)$.

B. canis affects androgen-related organs in male dogs. Acute inflammation associated with pain and swelling can cause orchitis or epididymitis, which can also be determined by hand examination $(2,16,17)$. Scrotal dermatitis can be formed as a result of licking by male dogs for comfort (2, 18). Chronic or prolonged infections can cause unilateral or bilateral testicular atrophy in breeding dogs $(17,19)$. Atrophy can result in reluctance to mate or loss of libido resulting from pain.

The systems in the body are also affected by bacteria. Discospondylitis in the thoracic vertebrae and lumbar vertebrae can be observed by radiography. Ophthalmologic examinations may result in endophthalmitis and recurrent uveitis (20-22). Non-suppurative meningitis is also reported at low rates (I3).

\section{Clinical Signs in Humans}

A small number of studies regarding clinical cases caused by $B$. canis have been published. The consequences of infection with other zoonotic brucellosis range from asymptomatic infections to various syndromes that can appear insidiously or suddenly. Acute brucellosis is a febrile disease with non-specific influenza-like symptoms, such as fever, chills, headache, weakness, backache, muscle aches, and lymphadenopathy (growth in the lymph nodes) and accompanying splenomegaly and/or hepatomegaly. Patients may experience sweating, especially in the evening. Humans acquire $B$. canis infection through direct contact with infected dogs or their reproductive or blood products. Clinical signs and symptoms include undulate fever, chills, malaise, splenomegaly, and peripheral lymphadenomegaly. Diagnosis is often complicated in humans because of the non-specific signs and symptoms coupled with a low index of suspicion by many physicians. If the disease is part of the differential diagnosis, culture is the only test available for diagnosing $B$. canis infection in humans, and confirmation is problematic because of low-level and intermittent bacteremia. Even if physicians suspect brucellosis, diagnoses may be missed because the commercially available serological tests screen for smooth Brucella species and will not detect antibodies against $B$. canis. Canine serological tests for $B$. canis infection have been adapted for use in humans, but test results should be interpreted with caution (23-28).

Published clinical cases associated with B. canis contain various representations suitable for this description. They vary from fatigue, nausea, tremor, night sweats, and fever with headaches to one symptom, such as mild tiredness or fatigue and intermittent fever. There is sometimes a long-standing syndrome of unknown fever in some people. Spleen and/or liver enlargement and increased liver enzymes have been reported in various cases. Weight loss, anemia, enlarged lymph nodes/ovaries, and abdominal pain have also been documented. Nausea, vomiting, and diarrhea have been described especially in children, and constant cough, sore throat, and conjunctival burning, in addition to night sweats, headache, numbness, and muscle pain, have been reported in one person. Serious complications have been reported, including endocarditis in a few cases. B. canis was associated with aortic valve and lower extremity aneurysm in one child and associated with calvarial osteomyelitis, epidural abscess, pleural effusion, and 
pulmonary nodules in another child. B. canis bacteremia and peritonitis were observed in an adult with concurrent hepatitis $C$ infection and cirrhosis. Liver disease is also a predisposing factor in rare cases of peritonitis associated with other Brucella species. Very few B. canis infections have been described in immunosuppressed individuals; however, this organism causes non-specific febrile syndromes in two individuals who are simultaneously infected with human immunodeficiency virus-I (28-32).

A laboratory worker exposed to a less virulent $M$-strain of $B$. canis developed symptoms similar to the symptoms caused by Brucella's wild-type strains $(24,33)$.

\section{Incubation Period}

There is less information about the incubation period of brucellosis caused by B. canis. Acute symptoms caused by other Brucella species usually occur within I-4 weeks. However, it may be insidious at first, and some cases are diagnosed 6 months after exposure $(28,31)$.

\section{Diagnosis}

Infertility, abortion, enlarged lymph nodes, swollen scrotum, and testicular atrophy are reported as clinical symptoms in $B$. canis infections; however, no clinical symptoms have been reported in some cases (34).

Bacterial isolation has been reported to be required from the tissue, discharge, blood, sperm, vertebra, or eye for a definitive diagnosis of $B$. canis cases. The results obtained should also be supported by positive serological agglutination tests, other serological titers, and hemoculture results. The variable amount and duration of bacteria in dogs make diagnosis difficult (35). Owing to this, a single negative blood culture does not show that there is no $B$. canis infection.

\section{Diagnostic Tests}

It can be difficult to diagnose brucellosis, which is caused by $B$. canis, in humans. The serological tests used to diagnose infections of the most commonly isolated zoonotic species (Brucella abortus, Brucella suis, and Brucella melitensis) do not detect antibodies against $B$. canis, and the tests used to detect $B$. canis antibodies are not usually available in diagnostic laboratories. In some studies, antibody reactions have been identified with the tests developed for this purpose or identified from analyses of dogs in the institute. These tests include microagglutination, tube agglutination, rapid slide agglutination test, and enzyme-linked immunosorbent assay $(28,36,37)$.

\section{Morbidity and Mortality}

There is very less information about $B$. canis infections in humans. Since relatively few clinical cases have been documented ( $<100$ since 2018) and most reported cases are mild, the virulence of this organism for humans may be low. However, the diagnosis of this disease is also insufficient given the low clinical suspicion and the difficulties of making a definite diagnosis among physicians. In a limited number of disease studies, some individuals who have been exposed to infected dogs have developed clinical findings or have had subclinical infection findings, such as laboratory abnormalities in liver function tests, whereas no evidence of disease was observed in others despite antibody detection. Nowadays, no deaths have been reported resulting from $B$. canis infections. The case mortality rate for untreated diseases caused by other Brucella species, including the highly virulent organism B. melitensis, is generally estimated to be $1 \%-2 \%$ or less. In serological studies, mostly conducted during the 1970s and early 1980s, <2\% of the studied populations were reported to have antibodies against $B$. canis, and the seroprevalence of $68 \%$ in dogs, $73 \%$ in veterinarians, and $57 \%$ in male blood donors was observed in people who are in contact with dogs at average levels in a study conducted at the Oklahoma Health Sciences Center in 1975. A previous study in the 1970 s reported that $13 \%$ of the hospitalized patients due to various diseases in Mexico are seropositive. During the last decade, two studies, one of which was published in the United States and the other in Turkey, found seroprevalence rates of $\leq 4 \%$ even during regular exposure to dogs. However, some studies indicate that B. canis infections may occur in some weakened/impoverished areas where dogs roam freely. In a previous study of a child with dog brucellosis in Argentina, 19\% of the people in the neighborhood were seropositive (3I, 38-43).

\section{Treatment}

Brucellosis is usually treated with long-standing antibiotics, and usually two or more drugs are combined in some part or all of the treatment in humans. Different antibiotics may be recommended depending on the patient's age, gestational status, and syndrome. Monotherapy has reported high levels of recurrence. If treatment is inadequate, recurrence may occur. Most recurrence often occurs within 3-6 months. Surgery may sometimes be required for localized focus. It has limited experimentation with B. canis in particular. However, standard antibiotic treatments for brucellosis appear to be effective in the cases reported. Several patients relapse as result of poor treatment $(24,25,28,31)$.

Future study is required to improve diagnostic assays for humans and animals and to generate policies to prevent the spread of disease $(23,28,44-46)$.

\section{CONCLUSION}

Brucellosis in dogs remains endemic to many areas worldwide and without stronger intervention measures will probably remain an under-recognized threat to human health and animal welfare. Potential hazards for humans should be discussed when a dog is diagnosed with brucellosis because antibiotics do not eliminate $B$. canis safely, and the level of risk in humans is now uncertain. Euthanasia in infected animals is often recommended in shelters and is also a choice in pets. Some authors suggest follow-up for periodic serological testing of pets starting treatment.

Peer-review: Externally peer-reviewed.

Author contributions: Concept - I.D., O.E.; Design - I.D., O.E.; Supervision - I.D., O.E.; Resource - I.D., O.E.; Materials - I.D., O.E.; Concept - I.D., O.E.; De- 
sign - I.D., O.E.; Supervision - I.D., O.E.; Resource - I.D., O.E.; Materials - I.D., O.E.; Data Collection and/or Processing - I.D., O.E.; Analysis and/or Interpretation - I.D., O.E.; Literature Search - I.D., O.E.; Writing - I.D., O.E.; Critical Reviews - I.D., O.Eta Collection and/or Processing - I.D., O.E.; Analysis and/or Interpretation - I.D., O.E.; Literature Search - I.D., O.E.; Writing - I.D., O.E.; Critical Reviews - I.D., O.E.

Conflict of Interest: The authors have no conflicts of interest to declare.

Financial Disclosure: The authors declared that this study has received no financial support.

\section{REFERENCES}

I. Pretzer SD. Bacterial and protozoal causes of pregnancy loss in the bitch and queen. Theriogenology 2008; 70: 320-6. [CrossRef]

2. Hollett RB. Canine brucellosis: outbreaks and compliance. Theriogenology 2006; 66: 575-87. [CrossRef]

3. Carmichael LE. Abortion in 200 Beagles. J Am Vet Med Assoc 1966; 149: 1126.

4. Wanke MM. Canine brucellosis. Animal Reproduction Science 2004; 82-83: 195-207. [CrossRef]

5. Feldman Nelson. Sección 7. Reproduccion En La Hembra Canına. Endocrınologıa Y Reproduccıon Canına Y Felına. 2007

6. Carmichael LE, Green EG. Canine brucellosis. In: Greene CE editor. Infectious Diseases of the Dog and Cat. WB Saunders Co: Philadelphia; 1990. pp. 573.

7. Carmichael LE, Joubert JC. Transmission of Brucella canis by contact exposure. Cornell Vet 1988; 78: 63-73.

8. Greene CE and George LW. Canine brucellosis. In Clinical Microbiology and Infectious Diseases of the Dog and Cat (ed. C. E. Greene), W. B. Saunders, Philadelphia, 1984; pp. 646-51.

9. Zoha SJ, Walsh R. Effect of a two-stage antibiotic treatment regimen on dogs naturally infected with Brucella canis. J Am Vet Med Assoc 1982; 180: 1474-5.

10. Weber A, Christoph H. Untersuchungen zur naturlichen Ubertragung von Brucella canis bei Hunden. Fortschr Veterinarmed 1982; 35: 35I-5.

II. Johnson CA, Walker RD. Clinical signs and diagnosis of Brucella canis infection. Compend Cont Educ Pract Vet 1992; 14: 770-2.

12. Meyer ME. The genus Brucella In: Shaw MP, Stulp H, Truper HG, Balous $A$, and Schlegel HG, editors. The prokaryotes. Springer-Verlag: New York; 198I. pp. 1063-74. [CrossRef]

13. Serikawa T, Muraguchi T, Nakao N, Irie Y. Significance of urine culture for detecting infection with Brucella canis in dogs. Jpn J Vet Sci 1978; 40: 353. [CrossRef]

14. Myer ME. Brucella organisms isolated from dogs: comparison of characteristics of members of the genus brucella. Am J Vet Res 1969; 30: 1751.

15. Ergene O, Celebi B, Kucukaslan I. Seroprevalance of Canine Brucellosis and Toxoplasmosis in Female and Male Dogs and Relationship to Various Factors as Parity, Abortion and Pyometra. Indian J Anim Res 2017; I-5. [CrossRef]

16. Moore JA, Bennett M. A previously undescribed organism associated with canine abortion. Vet Rec 1967; 80: 604-5. [CrossRef]

17. George LW, Duncan JR, Carmichael LE. Semen examination in dogs with canine brucellosis. Am J Vet Res 1979; 40: 1589-95.

18. Schoeb TR, Morton R. Scrotal and testicular changes in canine brucellosis: a case report. J Am Vet Med Assoc 1978; 172: 598-600.

19. Greene CE, Carmichael LE. Canine brucellosis. In: Greene CE, editor. Infectious diseases of the dog and cat. Philadelphia: WB Saunders, Co; 2006. pp. 369-81.

20. Gwin RM, Kolwalski JJ, Wyman M, Winston S. Ocular lesions associated with Brucella canis infection in a dog. J Am Anim Hosp Assoc 1980; 16: 607-10
21. Saegusa J, Ueda K, Got Y, Fujiwara K. Ocular lesions in experimental canine brucellosis. Jpn J Vet Sci 1977; 39: I8I-5. [CrossRef]

22. Riecke JA, Rhoades HE. Brucella canis isolated from the eye of a dog. J Am Vet Med Assoc 1975; 166: 583-4.

23. Hensel ME, Negron M, Arenas-Gamboa AM. Brucellosis in Dogs and Public Health Risk. Emerg Infect Dis 20l8; 24: 140I-6. [CrossRef]

24. Marzetti S, Carranza C, Roncallo M, Escobar Gl, Lucero NE. Recent trends in human Brucella canis infection. Comp Immunol Microbiol Infect Dis 2013; 36: 55-61. [CrossRef]

25. Javeri H, Jamieson S, Sehgal R, Cadena J. Brucella canis peritonitis. Infection 2014; 42: 195-7. [CrossRef]

26. Alton GG, Forsyth JRL. Brucella [online]. In Baron S, editor. Medical microbiology. 4th ed. New York: Churchill Livingstone; 1996. Available from: URL: http://www.ncbi.nlm.nih.gov/books/ NBK8572/ (Accessed 4 Jun 2007)

27. Centers for Disease Control and Prevention (CDC). Brucellosis [website online]. CDC; 2017 Sept. Available from: URL: https:// www.cdc.gov/brucellosis/ (Accessed 3 Mar 2018).

28. Cosford KL. Brucella canis: An update on research and clinical management. Can Vet J 2018; 59: 74-81.

29. Lawaczeck E, Toporek J, Cwikla J, Mathison BA. Brucella canis in a HIV-infected patient. Zoonoses Public Health 20II; 58: 150-2. [CrossRef]

30. Lucero NE, Maldonado PI, Kaufman S, Escobar Gl, Boeri E, Jacob NR. Brucella canis causing infection in an HIV-infected patient. Vector Borne Zoonotic Dis 2010; 10: 527-9. [CrossRef]

31. Olsen SC, Palmer MV. Advancement of knowledge of Brucella over the past 50 years. Vet Pathol 2014; 51: 1076-89. [CrossRef]

32. Piampiano P, McLeary M, Young LW, Janner D. Brucellosis: unusual presentations in two adolescent boys. Pediatr Radiol 2000; 30: 355-7. [CrossRef]

33. Traxler RM, Lehman MW, Bosserman EA, Guerra MA, Smith TL. A literature review of laboratory-acquired brucellosis. J Clin Microbiol 2013; 5l: 3055-62. [CrossRef]

34. Flores-Castro R, Carmichael LE. Canine brucellosis: current status of methods for diagnosis and treatment. In: 27th gaines veterinary symposium. 1977. pp. 17-24.

35. Taul LK, Powell HS, Baker OE. Canine abortion due to an unclassified Gram-negative bacterium. Vet Med Small Anim Clin 1967; 73: 543-4.

36. Ayala SM, Hasan DB, Celestino CA, Escobar GI, Zhao DM, Lucero NE. Validation of a simple universal IELISA for the diagnosis of human brucellosis. Eur J Clin Microbiol Infect Dis 2014; 33: 123946. [CrossRef]

37. Nomura A, Imaoka K, Imanishi H, Shimizu H, Nagura F, Maeda K, et al. Human Brucella canis infections diagnosed by blood culture. Emerg Infect Dis 2010; 16: II83-5. [CrossRef]

38. Tuon FF, Gondolfo RB, Cerchiari N. Human-to-human transmission of Brucella - a systematic review. Trop Med Int Health 2017; 22: 539-46. [CrossRef]

39. Monroe PW, Silberg SL, Morgan PM, Adess M. Seroepidemiological investigation of Brucella canis antibodies in different human population groups. J Clin Microbiol 1975; 2: 382-6.

40. Munford RS, Weaver RE, Patton C, Feeley JC, Feldman RA. Human disease caused by Brucella canis. A clinical and epidemiologic study of two cases. JAMA 1975; 231: 1267-9. [CrossRef]

4l. Strom Holst B, Lofqvist K, Ernholm L, Eld K, Cedersmyg M, Hallgren $G$. The first case of Brucella canis in Sweden: background, case report and recommendations from a Northern European perspective. Acta Vet Scand 2012; 54: 18. [CrossRef]

42. Sayan M, Erdenlig S, Stack J, Kilic S, Guducuoglu H, Aksoy Y, et al. A serological diagnostic survey for Brucella canis infection in Turkish patients with brucellosislike symptoms. Jpn J Infect Dis 2011; 64: 516-9. 
43. Weber A, Brunner H. Seroepidemiological investigations on the incidence of Brucella canis antibodies in man. Zentralbl Bakteriol Orig A 1977; 238: 237-43.

44. Atluri $V L$, Xavier MN, de Jong MF, den Hartigh AB, Tsolis RM. Interactions of the human pathogenic Brucella species with their hosts. Annu Rev Microbiol 201l; 65: 523-41. [CrossRef]
45. Lucero NE, Corazza R, Almuzara MN, Reynes E, Escobar Gl, Boeri $\mathrm{E}$, et al. Human Brucella canis outbreak linked to infection in dogs. Epidemiol Infect 2010; 138: 280-5. [CrossRef]

46. The Center for Food Security and Public Health. Brucellosis: Brucella canis. May 2018; I-10. 